\title{
Analysing Long-Term Landscape Changes in a Bornean Forest Reserve Using Aerial Photographs
}

\author{
Nor Rasidah Hashim*
}

Faculty of Environmental Studies, Universiti Putra Malaysia, 43400 Serdang, Selangor, Malaysia

\begin{abstract}
Aerial photographs have been widely used to monitor large-scale spatial changes taking place over long periods. In this study, the types and trajectories of landscape changes in Sabal Forest Reserve in the Malaysian state of Sarawak, Borneo over a period of 26 years (1972-1998) were investigated using 1:25,000 scale aerial photographs and ground surveys. The aerial photographs showed typical land use features such as forest clearing, fallows, roads, power line easements and houses, all of which could be easily identified and mapped by stereoviewing. Further analysis revealed that logging activities, which started in the 1970 s continued to increase through to the $1990 \mathrm{~s}$. In comparison, shifting cultivation began earlier and was seen to be widespread but was banned in Sabal by 1984, thus reflecting the conflict of interest between two major land users: shifting cultivators and foresters. Reforestation projects carried out after the ban appeared successful in increasing tree cover in former shifting cultivation areas. In conclusion this study has provided an interesting case study about how people in a remote area in Sarawak shaped their forested landscape.
\end{abstract}

Keywords: Forest reserves, Sarawak, logging, shifting cultivation.

\section{INTRODUCTION}

Aerial photographs chronicle land use history, demographic patterns and vegetation cover changes, and are valuable for studying pre- and post-disturbance landscape changes [1]. In Malaysia, as in many other Southeast Asian countries, the application of aerial photographs to map natural resources and land use started during the British colonial period and continued well into the $20^{\mathrm{th}}$ century [25]. Initially, 1:50,000 scale aerial photographs were taken by the Royal Air Force to produce 1:60,000 scale maps for the purpose of vegetation classification and land use planning by the government [6]. Later, these aerial photographs provided essential data for researchers to study ecological and social processes [7-9].

The advancement of geographic information system (GIS) has allowed for spatial analysis of aerial photographs to understand landscape changes occurring at large spatial scales and over long periods [10-17]. In Asia, Turner et al. [10] used GIS to analyze the land use/land cover changes of vegetation succession in Singapore using maps constructed from black and white 1:20,000 scale aerial photographs. In more remote Asian regions such as Borneo, however, studies on detailed long-term landscape changes using GIS analysis of aerial photographs are still few or only just beginning, although aerial photographs may have been commonly used for natural resource and land use surveys since the colonial era $[6,18,19]$. This paper therefore provides a much needed case study of land use/forest cover changes at the landscape level in the Borneo region, while highlighting several

*Address correspondence to this author at the Faculty of Environmental Studies, Universiti Putra Malaysia, 43400 Serdang, Selangor, Malaysia; Tel: +603 8946 7462; Fax: +603 8946 7463; E-mail: rasidah@env.upm.edu.my tropical forest management issues. Of particular interest is the conflict arising between forestry and agriculture, where the rights of native peoples are often at stake. Also, since timber production in Sarawak started to increase in the late 1970s, peaking in the early 1990s as shown in Fig. (1), the land use patterns will be discussed in relation to this socioeconomic perspective.

The main objective of this study is to reconstruct land use changes and forest regenerations in Sabal Forest Reserve in the Malaysian state of Sarawak, Borneo, during the period of 26 years (1972-1998) using the interpretation and analysis of aerial photographs. The objective is guided by the following questions:

1. What are the common land use types and how extensive is each land use type?

2. What are the main trajectories and types of land use or forest succession?

3. Do the temporal changes in land use result in greater fragmentation of the landscape?

\section{MATERIALS AND METHODS}

\section{Location and History of Sabal}

Sabal Forest Reserve (Sabal), is located between latitudes of $0^{\circ} 58^{\prime}-01^{\circ} 04^{\prime}$ North and longitudes of $110^{\circ} 51^{\prime}-110^{\circ} 57^{\prime}$ East. Although located in the relatively interior part of Sarawak, Sabal is accessible by road because it straddles the only asphalt road from the state capital of Kuching to the town of Sri Aman.

The general topography of Sabal consists of undulating and low-lying lands in the north and steeper hills in the Klingkang range in the south. The highest point is Gunung 


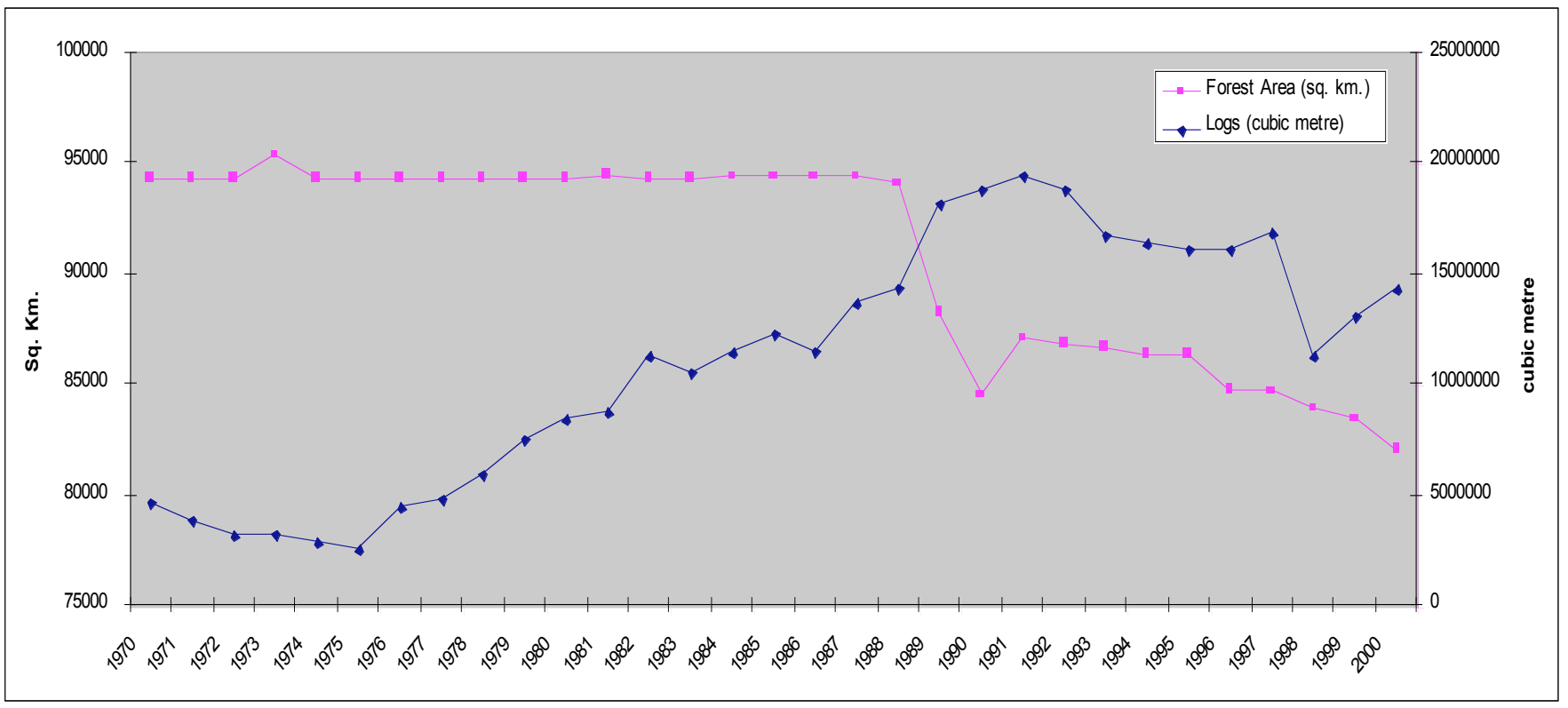

Fig. (1). Total forest area (sq. km.) and timber logs production $\left(\mathrm{m}^{3}\right)$ in Sarawak for the period of 30 years $(1970-2000)$ [40].

Gaharu at $820 \mathrm{~m}$. above sea level (Fig. 2). The high elevation of the Klinkang range influences the climate and hydrology of the area $[20,21]$. The original vegetation in the northern part of Sabal was mostly tropical heath forest with patches of mixed dipterocarp forest that becomes increasingly dominant in the southern part towards the Klingkang Range [20].

Sabal covers an area of approximately 7833 ha (or less than $1 \%$ of the total forest reserve area in Sarawak) and was gazetted as a forest reserve in 1927 [22]. This means Sabal is one of the permanent sources of the state's supply of timber and other forest produce, which admits limited rights or privileges for local people to utilize forest produce [22, 23]. Logging in Sabal started in the 1970s and logging licenses are given out to logging concessionaires. During logging operations, medium to large timber was routinely transported out of the area using trucks and tractors even after 1999 when heli-logging (logging using a helicopter) was introduced in the area. As a result, felled tree stumps of diameters $30-60 \mathrm{~cm}$ were found in all of the logged-over forest fragments that I surveyed [24].

The surrounding areas are mostly populated by Iban villagers, who carried out shifting cultivation within the forest reserve even after their forceful eviction in 1984 [23]. The non-nomadic Ibans are well known for conducting shifting cultivation in Borneo [25]. Although it is not known when the Ibans first started conducting shifting cultivation in Sabal, this practise intensified in the early 1970s and continued into the early 1980s [23, 24]. In 1981, the areas that were formerly used for shifting cultivation started to be planted with the exotic Australian timber species, Acacia mangium and later interplanted with the native Bornean species, Shorea macrophylla in the 1990s under the Sabal reforestation and agroforestry programmes $[23,26]$. These community-based programmes were started to reduce shifting cultivation and to promote sedentary agriculture and paid employment [23]. In 1981, the afforested area covered a mere 30 ha, but by the end of 1995, approximately 2363 ha of Sabal was afforested with native and exotic timber species, of which Acacia mangium was the most commonly planted species $[22,24]$.

\section{Land Use and Forest Successional Stages Classification}

I spent several months in Sabal in 1998 and 1999; first to study the general landscape and vegetation types and then to conduct extensive ground flora surveys in both tree plantations and logged-over forests. During this period, I interviewed the staff at Sabal and some Iban villagers in the surrounding area to get some historical and socio-economic perspectives that were useful to reconstruct the narrative of Sabal. The Sarawak Forest Department also provided maps of the plantation plots and Sabal boundary that I used to interpret the aerial photographs.

The classification of land use and forest successional stages was based on the forms, shapes and greyscale of the vegetation, forest canopy and land use seen in the photographs, and in combination with the information obtained from ground surveys (mentioned above). The five forest successional stage and/or land use classes being used in this study were as follows:

1. Clearing ("C"): 0 - 25\% vegetation cover. Light grey polygons having no or little ground cover. This class consists of clearings and areas that are vegetated mainly by grasses, ferns and scattered small trees of height $<2$ meters. Dominant plant species included the ferns: Dicranopteris linearis and Pteridium caudatum, and the shrubs Melastoma malabathricum and Dillenia suffruticosa.

2. Early-successional forest ("ESF"): 26 - 50\% vegetation cover. The polygons of this class showed up as light grey. This class is composed of earlysuccessional forest fallows after shifting cultivation. Plant species diversity in these fallows is relatively low [26]. Dominants include ferns of the same species as in class (i), sedges mainly (Scleria purpurascens) and shrubs of Melastoma malabath- 


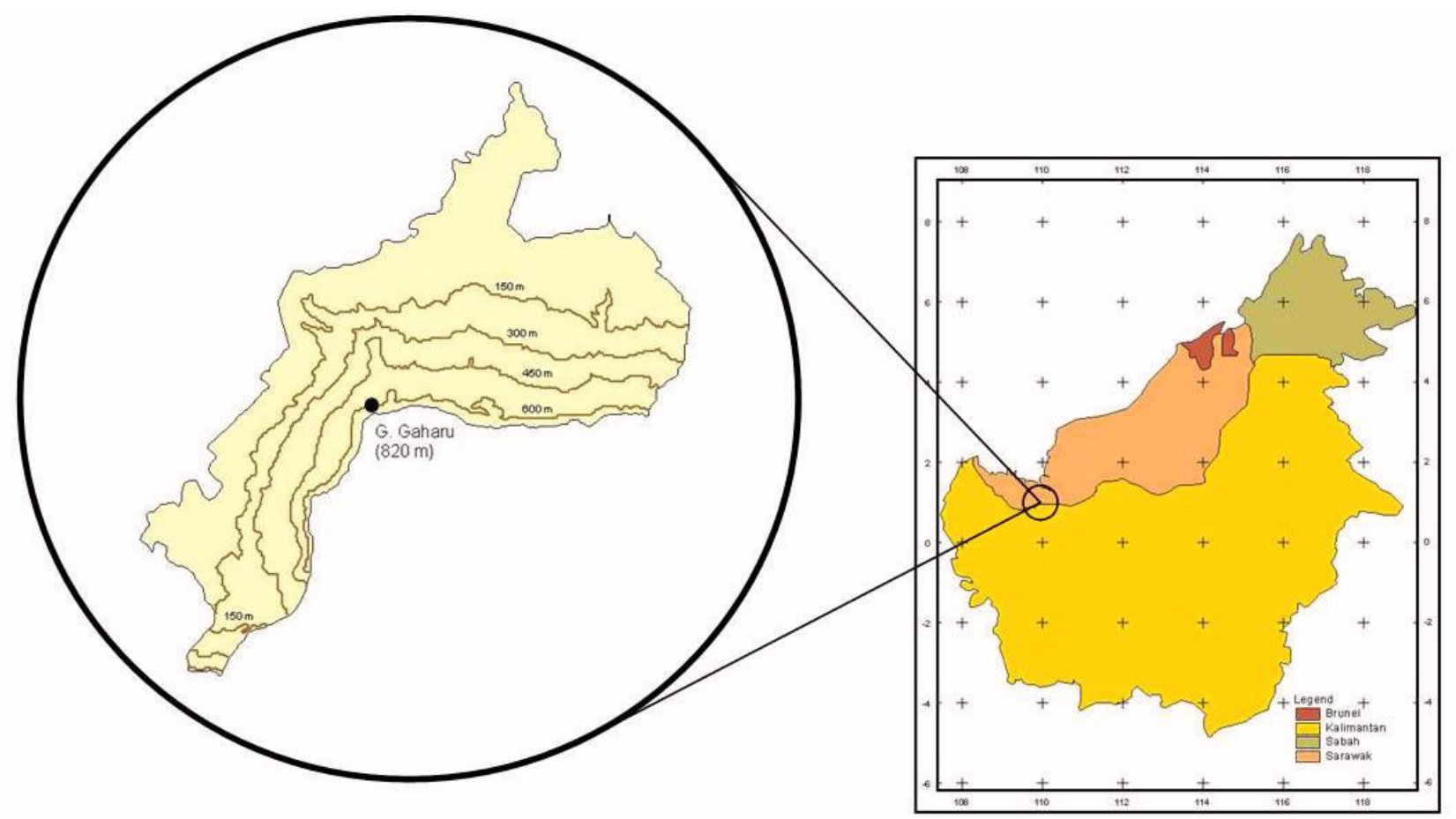

Fig. (2). Location of Sabal Forest Reserve, Sarawak, Malaysian Borneo. The enlarged study area is shown with contour elevations at $150 \mathrm{~m}$ intervals.

ricum, Dillenia suffruticosa, and trees of Macaranga species, Callicarpa species and Ploiarium alternifolium with an average tree height of 5-10 meters. Tree plantations (mostly Araucaria cunninghamii and Swietenia macrophylla) with very low understory tree diversity were also included in this category.

3. Mid-successional forest ("MSF"): $51 \quad$ - $75 \%$ vegetation cover. Land use polygons of this class showed up as dark grey with medium-sized gravels of canopy appearance on aerial photographs. This land use/vegetation cover class consists of midsuccessional forest fallows and tree plantations with relatively higher tree species diversity than in class (ii). In tree plantations, ferns mainly Dicranopteris linearis, Pteridium caudatum, Blechnum sp., and Stenochlaena palustris and the sedge, Scleria purpurascens, are abundant in the understory. Tree species diversity is relatively low and consists of mainly Dillenia suffruticosa, Fagraea crassipes, Macaranga spp., Alstonia angustifolia, Melastoma malabathricum and Ploiarium alternifolium as assessed in survey plots [24]. The average tree canopy height in this class is between $15-20 \mathrm{~m}$.

4. Forest ("F"): 76 - 100\% vegetation cover. The polygon colour is darker than that of class (iii) and canopy appearance is shown as medium- to largesized gravels on aerial photographs. The tree canopy height is $>20 \mathrm{~m}$. This class is composed of large tracts of forests intermittently broken by logging roads. Ground truthing confirmed that logging in this part of Sabal was ongoing and extensive. These forests are of heath and mixed dipterocarp types. Heath forests usually have lower diversity than mixed dipterocarp forests, with approximately 86 tree species $\mathrm{ha}^{-1}[27]$.

5. Logged-over forest fragments ("FF") were classified as a separate class to indicate forest fragmentation. In terms of percent canopy cover, logged-over forest fragments fell under either category (iii) or (iv), depending on the amount of logging done. Tree species diversity in these fragments was quite high with more than 50 tree families found in survey plots [24].

\section{Aerial Photo Interpretation}

The Sarawak Land and Survey Department took 1:25000 scale aerial photographs of Sabal four times over the 26 year-period: in 1972, 1976, 1982, and 1998. These photographs were taken using a camera attached to a twinengine aircraft. Unfortunately, the areas covered by the aerial surveys were not the same for all years. In 1972, the aerial photographs showed only $40 \%$ (or 3105 ha) of Sabal, whereas in 1976, 1982 and 1998, the aerial photographs covered $75 \%$ (or 5869 ha) of Sabal. Consequently, aerial photo interpretations were carried out for the coincident areas of 1972-1998.

A mirror stereoscope was used to interpret the aerial photographs because this equipment was relatively easy to use and its stereoviewing provided a sense of depth (or height) of the two-dimensional images, which greatly assisted in my interpretation process. The interpretation involved delineating the boundaries of specific land use/forest successional stages based on the categories mentioned in "Land use and forest successional stages classification" section above. The polygons of land use/forest successional stage of the approximate size of or 
greater than $1 \mathrm{~mm} \times 5 \mathrm{~mm}$ as well as visible lines representing roads that were delineated on the aerial photos were then traced onto a clear plastic sheet. These tracings were later transferred onto an enlarged topographic map (original scale 1:50000) to generate the final map to be digitized and analyzed in GIS. Normally, the transfer of images to a base map of a different scale is performed using a zoom transfer scope $[14,16,28]$. However, a zoom transfer scope was not available for this study. Nevertheless, the errors due to transfer without rectification were likely to be small because careful steps were made to ensure that clear landmarks were seen on the photographs and that only the centre of the photographs was used for tracing $[10,12]$.

\section{Spatial and Statistical Analyses}

For the spatial analysis in GIS, vector layers consisting of polygons (of the land use, forest successional stage and the mapped boundary of Sabal) and lines (representing several types of roads) were digitized, georeferenced and projected to the Malaysian rectified skew orthomorphic (RSO) projection. Finally, a descriptive statistics for each map layer were calculated for the following landscape changes:

1. Forest fragmentation - frequency and size of land use polygons, especially forest fragments.

2. Land use change/forest succession - size and percentage of land use transitions between two time periods (calculated from the GIS map overlay of two different years). In this analysis, an "upward" transition means a conversion from a more disturbed to a less-disturbed vegetation/forest state, whereas a "downward" transition means a conversion from a less disturbed to a more-disturbed vegetation/forest state.

\section{RESULTS}

\section{Land Use Change and Forest Succession}

The types of anthropogenic disturbance in Sabal were restricted to several types but the intensities of each one at any one time varied. In the 1972 photographs, continuous forests covered $81 \%$ of the 3105 ha study area, however, in 1998 forest cover was further reduced by $29 \%$ to cover only $52 \%$ of the study area. Forest conversion in the first ten years (1972-1982) was mostly for shifting agriculture, as indicated by the existence of land clearing and regenerating fallows of different ages. The percentages of clearing in a year were relatively small $(<3 \%)$ whereas the percentages of regenerating forests (ESF and MSF) ranged from 4\% to $30 \%$ over the 10-year period, whilst mid-successional forests, which were mostly tree plantations covered a vast area in 1998 (Fig. 3d).

Logging roads also rapidly increased in coverage and frequency during the study period. In the 1982 photographs, logging roads were seen to criss-cross the areas that were classified as large forests, thereby indicating active logging operations. Like shifting cultivation, logging seemed to spread from the main road but logging roads existed only in the southern side where the forests were located. By the 1980 s, logging roads were seen to penetrate deep into the forests at high elevations as shown in Figs. $(\mathbf{2}, \mathbf{3})$. Between 1972 and 1982, logging roads appeared to be preceding shifting cultivation but after 1982 the expansion of logging roads was not followed by similar expansion of shifting cultivation as shown in Fig. (3).

\section{Forest Fragmentation}

The abundance of land use/forest successional stage polygons peaked in 1982, with a total of 56 polygons coinciding with the smallest overall mean polygon size. In that year, forest fragments, clearings and mid-successional forests (MSF) were most numerous. In the same year, the mean polygon size for ESF was largest, although the number of early-successional forests (ESF) was lowest over the 26year period. The number and the mean size of polygons for large forests $(\mathrm{F})$ decreased steadily over the 26-year period. Further analysis revealed that the mean sizes for land clearings (C) and forest fragments (FF) were relatively small, whereas ESF and MSF occurred in medium-size patches (Table 1).

\section{Land Use/Forest Succession Trajectories}

The results for the transition analysis are shown in Table 2. The first transition analysis (1976 to 1982) found 15 pathways of land use/forest transition, consisting of 3 "upward" transitions, 7 "downward" transitions and 4 "no" transitions. The second and third transition analyses (1976 to 1982 and 1982 to 1998 , respectively) each found 17 pathways of land use/forest transition, consisting of 5 "upward" transitions, 7 "downward" transitions and 4 "no" transitions. Between 1972 and 1976, the "upward" transitions were made up of a very small area (29 ha) compared to the "downward" transitions (565 ha). In contrast, the opposite trends were found for the latter two transitions: 371 ha for "downward" transitions and 696 ha for "upward" transitions between 1976 and 1982; and an almost balanced comparison for 1982-1998 (311 ha for "downward" transitions and 338 ha for "upward" transitions). Since an "upward" transition means a conversion from a more disturbed to a less-disturbed vegetation/forest state, the later two longer interval periods (6 years and 16 years) showed some improvement or forest regeneration. In contrast, in the 1970s, more forest/vegetation disturbance and degradation was taking place than forest/vegetation improvement.

For the four-year transition period, the transitions with values of $\geq 50 \%$ were those of early-successional forest to clearing, forest to early-successional forest, mid-successional forest to mid-successional forest, forest to forest fragment and forest to forest. For the 6-year transition period, only three transitions had values of $\geq 50 \%$, which were those of early-successional forest to clearing, early-successional forest to mid-successional forest, and forest to forest. For the 16 -year transition period, the five transitions had values of $\geq$ $50 \%$ were those of mid-successional forest to clearing, midsuccessional forest to early-successional forest, midsuccessional forest to mid-successional forest, forest fragment to forest fragment and forest to forest. For all three transition periods, a large portion of forest still remained as forest. 

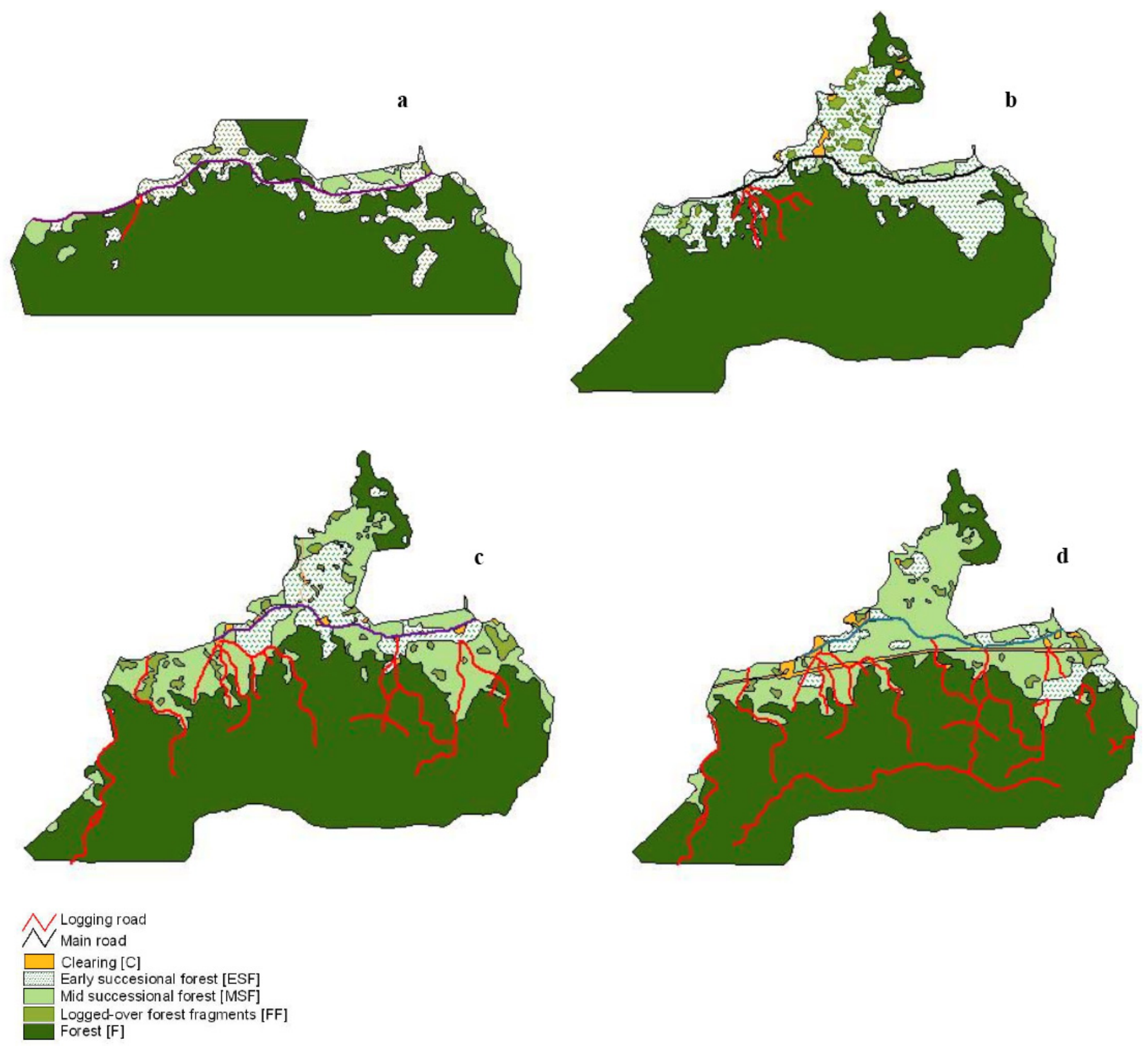

Fig. (3). Land use/forest succession map of Sabal for 1972 (a), 1976 (b), 1982 (c), 1998 (d).

\section{DISCUSSION}

Using four sets of aerial photographs and extensive ground surveys, I set out to understand how people in Sarawak changed their forested landscape through shifting cultivation, logging and some form of forest protection. Firstly, I found that working with such rich graphical data $(1: 25,000$ scale aerial photographs of relatively good conditions) had both its advantages and disadvantages. The aerial photographs showed clearly forests, clearing, fallows, roads, power line easements and houses. Several different types of roads could be identified and mapped; the extent and abundance of logging roads could be seen cutting through the forests and these roads were ordinarily not straight but had branches that looked like root hairs, the main roads were always straighter than the other types of roads, and the roads that were constructed by shifting cultivators were usually meandering and frequently led to land clearing or villages.

However, the 1:25,000 scale aerial photos were technically inappropriate for evaluating forest species diversity or classifying forest types based on very small differences in structural and compositional characteristics. For example, although the sapling stages of tree plantations were easily distinguished from continuous forests, the later stages of tree plantations (mature trees) were not easily distinguishable from the continuous forests. This could be due to the absence or lack of undergrowth cutting in the plantations, thereby allowing secondary forests to regenerate. Also, as there was little clear and detectable boundary between forest fragments and mid-successional forests, I might have overestimated the conversion of forest fragments into mid-successional forest. Late-succession forests seen in satellite images of coarser scales also are difficult to separate 
Table 1. Land Use/Forest Successional Stage Polygons for All Four Years (1972, 1976, 1982 and 1998). Clearing is Forest Clearing, ESF is Early-Successional Forests, MSF is Mid-Successional Forests, Fragment is Forest Fragment and Forest is Large Tracts of Forest

\begin{tabular}{|c|c|c|c|c|c|c|}
\hline & Clearing & ESF & MSF & Fragment & Forest & All \\
\hline \multicolumn{7}{|l|}{1972} \\
\hline No. of polygons & 1 & 13 & 10 & 11 & 2 & 37 \\
\hline Minimum polygon size (ha) & 2 & 1 & 1 & $\sim 0$ & 127 & $\sim 0$ \\
\hline Maximum polygon size (ha) & - & 366 & 23 & 4 & 2408 & 2408 \\
\hline Mean polygon size (ha) & - & 33 & 11 & 2 & 1268 & 84 \\
\hline$\%$ of total study area & 0 & 14 & 4 & 1 & 82 & 100 \\
\hline \multicolumn{7}{|l|}{1976} \\
\hline No. of polygons & 5 & 8 & 9 & 22 & 1 & 45 \\
\hline Minimum polygon size (ha) & 1 & 1 & 3 & $\sim 0$ & 1946 & $\sim 0$ \\
\hline Maximum polygon size (ha) & 14 & 898 & 42 & 12 & 1946 & 1946 \\
\hline Mean polygon size (ha) & 4 & 118 & 14 & 3 & - & 69 \\
\hline$\%$ of total study area & 1 & 30 & 4 & 2 & 62 & 100 \\
\hline \multicolumn{7}{|l|}{1982} \\
\hline No. of polygons & 17 & 3 & 10 & 25 & 1 & 56 \\
\hline Minimum polygon size (ha) & $\sim 0$ & 1 & 3 & $\sim 0$ & 1627 & $\sim 0$ \\
\hline Maximum polygon size (ha) & 5 & 287 & 402 & 29 & 1627 & 1627 \\
\hline Mean polygon size (ha) & 2 & 129 & 94 & 5 & - & 56 \\
\hline$\%$ of total study area & 1 & 12 & 30 & 4 & 52 & 100 \\
\hline \multicolumn{7}{|l|}{1998} \\
\hline No. of polygons & 5 & 7 & 9 & 19 & 1 & 41 \\
\hline Minimum polygon size (ha) & 1 & 4 & 6 & 0 & 1564 & $\sim 0$ \\
\hline Maximum polygon size (ha) & 94 & 81 & 517 & 14 & 1564 & 1564 \\
\hline Mean polygon size (ha) & 23 & 28 & 128 & 4 & - & 76 \\
\hline$\%$ of total study area & 4 & 6 & 38 & 2 & 50 & 100 \\
\hline
\end{tabular}

into several classes as found by other researchers [29, 30]. Similarly, the boundaries between logged and unlogged forests were difficult to make out on the 1:25000 scale aerial photographs.

Some of these misclassifications could be rectified by using higher resolution panchromatic aerial photographs to distinguish different forest types or tree species. Moreover, the large tracts of forests seen in the photographs were assumed to be intact, but in actuality the presence of logging roads meant that ground-level environmental degradation was occurring in the forests [31, 32]. Therefore further GIS spatial analysis (BUFFER analysis) may provide some measure of forest degradation.

Nonetheless, one of the strengths of aerial photograph interpretation lies in its usefulness to monitor long-term landscape changes in relation to road construction, particularly forest conversion for shifting cultivation and logging. One of the well-known tropical forest degradation processes is road construction, which paves the way for further destruction and encroachment of forests [33-35]. This sequence of events in Sabal could be clearly seen in the aerial photographs, i.e. the presence of clearing on both of sides of the Kuching-Sri Aman main road, which was opened in 1962 [36] (Fig. 3). Although this study's analysis is somewhat dated (the last available aerial photographs were taken in 1998), a quick scan of Sabal's current landscape using a satellite image from Google Earth [37] showed that the extent of logging roads was similar to the image recorded in 1998 which means logging in the forest reserve has reached its maximum capacity for some time now.

Secondly, I found that the information obtained during ground surveys including interviews were extremely useful to interpret the aerial photographs. For example, I learned through interviews that reforestation projects in former shifting cultivation sites began in the early 1980s. Later during field surveys I discovered some logged-over forest fragments were also being "reforested" through a practice of strip-clearing the forest to plant Shorea macrophylla. This might have degraded the vegetation structure and composition further, as indicated by the aerial photograph analysis, which showed some conversion of forest fragments into mid-successional forest class for the study period of 1982-1998.

Thirdly, it was found that over the 26-year study period, the fragmentation of Sabal's forested landscape was 
Table 2. Size of Land Use Forest Successional Stage Transitions. Black Pathway Type Denotes No Transition. Red Pathway Type Denotes Downward Transition (from Less Disturbed to More Disturbed Forest Types). Blue Pathway Type Denotes Upward Transition (from More Disturbed to less Disturbed Forest Types). Percentage Values $\geq 50 \%$ in Bold. Superscript Denotes Transition Number

\begin{tabular}{|c|c|c|c|c|c|c|}
\hline Pathway Type & $\begin{array}{l}\text { 4-Year Transition } \\
\text { (1972-1976) (ha) }\end{array}$ & $\%$ & $\begin{array}{l}\text { 6-Year Interval } \\
(1976-1982)(h a)\end{array}$ & $\%$ & $\begin{array}{c}\text { 16-Year Transition } \\
\text { (1982-1998) (ha) }\end{array}$ & $\%$ \\
\hline 1. Total Clearing $(\mathrm{C})$ & 24.5 & & 27.8 & & 94.5 & \\
\hline $\mathrm{ESF} \rightarrow \mathrm{C}$ & $18.5^{2}$ & 76 & $18.7^{2}$ & 67 & - & - \\
\hline $\mathrm{MSF} \rightarrow \mathrm{C}$ & - & - & $0.6^{3}$ & 2 & $84.7^{2}$ & 90 \\
\hline 2. Total Early-successional Forest (ESF) & 849.6 & & 530 & & 202.7 & \\
\hline $\mathrm{ESF} \rightarrow \mathrm{ESF}$ & $387.2^{4}$ & 46 & $243.6^{4}$ & 46 & $61.6^{3}$ & 30 \\
\hline $\mathrm{C} \rightarrow \mathrm{ESF}$ & - & - & $11.0^{5}$ & 2 & $1^{4}$ & 0 \\
\hline $\mathrm{MSF} \rightarrow \mathrm{ESF}$ & $26.7^{5}$ & 3 & - & - & $126.2^{5}$ & 62 \\
\hline $\mathrm{MSF} \rightarrow \mathrm{MSF}$ & $84.7^{8}$ & 69 & $83.6^{8}$ & 11 & $692.6^{8}$ & 63 \\
\hline $\mathrm{C} \rightarrow \mathrm{MSF}$ & - & - & $2.9^{9}$ & $\sim 0$ & $13.5^{9}$ & 1 \\
\hline $\mathrm{ESF} \rightarrow \mathrm{MSF}$ & $17.6^{9}$ & 14 & $665.2^{10}$ & 86 & $316^{10}$ & 29 \\
\hline $\mathrm{FF} \rightarrow \mathrm{MSF}$ & - & - & $1.2^{11}$ & $\sim 0$ & $44.7^{11}$ & 4 \\
\hline $\mathrm{F} \rightarrow \mathrm{MSF}$ & $21.1^{10}$ & 17 & $19.1^{12}$ & 2 & $39.3^{12}$ & 4 \\
\hline 4. Total Forest Fragments (FF) & 80.1 & & 113.7 & & 71.3 & \\
\hline $\mathrm{FF} \rightarrow \mathrm{FF}$ & $10.3^{11}$ & 13 & $44.8^{13}$ & 39 & $68.7^{13}$ & 96 \\
\hline $\mathrm{ESF} \rightarrow \mathrm{FF}$ & $10.6^{12}$ & 13 & - & - & - & - \\
\hline $\mathrm{FF} \rightarrow \mathrm{F}$ & - & - & - & - & $2.5^{17}$ & $\sim 0$ \\
\hline TOTAL LAND USE (ha) & 3060.1 & & 3060.5 & & 3060.7 & \\
\hline
\end{tabular}

positively correlated with the frequency and intensity of land use, where the highest number of forest fragments was found to coincide with the highest level of shifting cultivation as inferred from the extent of land clearing, early-successional and mid-successional forest fallows in the 1982 photographs (Table 1). Shifting cultivation mostly depends on natural soil fertility and nutrient regeneration. Thus, in Sabal, the lowintensity use of land for shifting cultivation was apparent in the sizes and the numbers of forest clearing in any given year, which covered a small portion of the total area of Sabal, that is less than $3 \%$, compared to the relatively large total area that had been under shifting cultivation, which was more than $60 \%$ of Sabal in 1982 (Table 1).
Fourthly, the 1972, 1976 and 1982 photographs showed us that shifting cultivation was widespread in Sabal. The Forest Department evicted shifting cultivators in the forest reserve in the 1980s [23], clearly indicating the conflict of interest between the two major land users in Sarawak at the time [4]. In this case, the foresters were clearly exerting their rights on Sabal's natural resource. A similar conflict between agriculture and forestry also took place in Peninsular Malaysia, forcing the federal government to enact a national land code that required agriculture to be conducted in zoned areas while preventing the encroachment of forest reserves [38]. So it remains to be seen how long the foresters have the upper hand in Sarawak and elsewhere in Borneo when the pressures to convert forests into oil palm plantations are now 
burgeoning [39]. As Sabal's primary function is for timber production, logging duly intensified in 1980s-1990s (Fig. 3) as the overall production of timber in Sarawak reached its peak (Fig. 1) [40] to meet high demands from both within and outside of Malaysia [4, 41]. Also around this time (in the 1970s and 1980s), some researchers' argued that shifting cultivation was to be blamed for forest destruction and degradation but in recent decades others have argued that commercial logging was the worse culprit [8, 23, 42-44]. In Sabal, the eviction of Iban shifting cultivators took place in the 1980 s so the action can be interpreted as being more economically than environmentally motivated.

Finally, this study has also found that vegetation regeneration was taking place in the former shifting cultivation sites. Along with the forest department's reforestation projects that aimed at restocking timber species, natural regeneration was taking place as well, especially with the existence of forest fragments that act as seed banks and suitable habitats for seed dispersers [24]. This means that a forestry management that wishes to conserve biological diversity needs to consider the ecological functions of these forest fragments and natural regenerations and take appropriate actions to protect the already degraded habitats in Sabal.

\section{CONCLUSION}

It is concluded that the combination of spatial analysis of aerial photographs and ground surveys was successful in revealing and quantifying the changes of land use and forest cover in Sabal. As mentioned, the extent and abundance of different types of roads could be clearly identified and mapped. However, the separation of certain land use types and forest successional stages were more difficult to assess from the aerial photographs. There was a strong positive relationship between the construction of a major road and the extent of land use in Sabal during the 26-year study period. The government ban on shifting cultivation and later the extensive reforestation projects appeared successful in increasing tree cover in former shifting cultivation areas. The legislation and employment opportunities brought about by the reforestation projects also worked well to prevent further conflict between the shifting cultivators and foresters, and so the forest reserve was used primarily for timber production thereafter.

\section{ACKNOWLEDGMENTS}

I am grateful to Dr. Stuart Davies and Dr. Ian Turner for providing useful comments on earlier drafts of this paper. Two anonymous reviewers also made useful comments to improve this paper. My many thanks to the students and staff of IBEC for their support and friendship during my stay at UNIMAS. This study also benefited greatly from the support and help of the Sarawak Forestry staff, especially Rufus and Meno in Sabal, and Tuan Haji Awang Seruji in Kuching. Wan Faridah Akmal Wan Jusoh (Universiti Putra Malaysia) obtained the data for Fig. (1) and Mohd Shahrudin Abd Manan (Universiti Putra Malaysia) helped with the graphics. I would also like to acknowledge the Department of Mapping Malaysia (Sarawak branch) for allowing me to use the aerial photographs of Sabal. Finally I thank the International Tropical Timber Organization (grant no.
045/98A) and Mr. and Mrs. Erik Stappers for generously funding this study.

\section{REFERENCES}

[1] Hoffer RM. Challenges in developing and applying remote sensing to ecosystem management. In: Sample VA, Ed. Remote sensing and GIS in ecosystem management, Washington DC: Island Press 1994; pp. 25-40.

[2] Watson JG. Mangrove forests of the Malay Peninsula. Kuala Lumpur: Forest Department 1928.

[3] Wong IFT. The present land use of West Malaysia. Kuala Lumpur: Ministry of Agriculture and Lands Malaysia 1966.

[4] Majid CF. The challenge of sustainable forests: forest resource policy in Malaysia, 1970-1995. St Leonards: Allen \& Unwin 1999.

[5] Symington CF. Foresters' manual of dipterocarps. Kuala Lumpur: Forest Research Institute Malaysia 2004.

[6] Francis EC, Wood GHS. Classification of vegetation in N. Borneo from aerial photographs. Malay Forest 1955; 1: 38-44.

[7] Whitmore TC. Tropical rain forest of the far east, second edit. Oxford: Clarendon Press 1984.

[8] Ichikawa M. Degradation and loss of forest land and land-use changes in Sarawak, East Malaysia: a case study of native land use by the Iban. Ecol Res 2007; 22: 403-23.

[9] Gianno R, Bayr KJ. Semelai agricultural patterns: toward an understanding of variation among indigenous cultures in southern Peninsular Malaysia. J Southeast Asian Stud 2009; 40(1): 153-85.

[10] Turner IM, Wong YK, Chew PT, Ibrahim A. Rapid assessment of tropical rain forest successional status using aerial photographs. Biol Conserv 1996; 77: 177-183.

[11] Tanaka H, Nakashizuka T. Fifteen years of canopy dynamics analyzed by aerial photographs in a temperate deciduous forest, Japan. Ecology 1997; 78(2): 612-20.

[12] Lindgren DT. Land use planning and remote sensing. Dordrecht: M. Nijhoff Publishers 1985.

[13] Apan, AA. Land cover mapping for tropical forest rehabilitation planning using remotely-sensed data. Int J Remote Sensing 1997; 18(5): 1029-49.

[14] Thomlinson JR, Serrano M, Lopez TM, Aide TM, Zimmerman JK. Land-use dynamics in a post-agricultural Puerto Rican landscape (1936-1988). Biotropica 1996; 28(4a): 525-36.

[15] Herwitz SR, Slye RE, Turton SM. Redefining the ecological niche of a tropical rain forest canopy tree species using airborne imagery: long-term crown dynamics of Toona ciliata. J Trop Ecol 1998; 14: 683-703.

[16] Foster DR, Fluet M, Boose ER. Human or natural disturbance: landscape-scale dynamics of the tropical forests of Puerto Rico. Ecol Appl 1999; 9(2): 555-72.

[17] Steininger, MK. Satellite estimation of tropical secondary forest above-ground biomass: data from Brazil and Bolivia. Int J Remote Sensing 2000; 21(6 \& 7): 1139-57.

[18] Brunig EF. The classification of forest types in Sarawak. The Malay Forest 1969; xxxii (2): 143-79.

[19] Andriesse JP. The Soils of West Sarawak (East Malaysia) I. Kuching: Government Printing Office 1972.

[20] Brunig EF. Ecological studies of the Kerangas forests of Sarawak and Brunei. Kuching: Borneo Literature Bureau 1974.

[21] Newbery DM, Renshaw E, Brunig EF. Spatial pattern of tree in Kerangas forest, Sarawak. Vegetatio 1986; 65: 77-89.

[22] Sarawak Forest Department. 2008. Available from: http://www.forestry.sarawak.gov.my [cited: $25^{\text {th }}$ Dec 2008).

[23] Morningstar OR, Knight NM. Implementing agroforestry in Sarawak: a final report on the Sabal pilot agroforestry project. Kuching: Forest Research Report RR1 1990.

[24] Hashim NR. Land-use dynamics, tree diversity and soil properties in Sabal forest reserve, West Sarawak, Malaysia. MSc [Thesis in Forest Ecology]. Universiti Malaysia Sarawak, Malaysia 2000.

[25] Freeman D. The Iban of Borneo. Kuala Lumpur: S.Abdul Majeed \& Co. 1992.

[26] Butt G. Semi detailed site evaluation of Sabal forest reserve (Northern Half): a preliminary report. Kuching: soil survey unit research section, Sarawak Forest Department 1983.

[27] Davies SJ, Becker P. Floristic composition and stand structure of mixed dipterocarp and heat forests in Brunei Darussalam. J Trop For Sci 1996; 8(4): 542-69. 
[28] Green DR, Cummins R, Wright R, Miles J. A methodology for acquiring information on vegetation succession from remotely sensed imagery. In: Haines-Young R, Green DR, Cousins S, Eds. Landscape ecology and geographic information systems, London: Taylor \& Francis 1993; pp. 111-28.

[29] Tanner EVJ, Kapos V, Adams J. Tropical forests- spatial pattern and change with time, as assessed by remote sensing. In: Newbery DM, Prins HHT, Brown ND, Eds. Dynamics of tropical communities. Cambridge: Cambridge University Press 1998; pp. 599-616.

[30] Stibig HJ, Malingreau JP. Forest cover of insular Southeast Asia mapped from recent satellite images of coarse spatial resolution. Ambio 2003; 32(7): 469-75.

[31] Wyatt-Smith J, Foenander EC. Damage to regeneration as a result of logging. Malay Forest 1962; 25: 40-4.

[32] Pinard MA, Howlett B, Davidson D. Site conditions limit pioneer tree recruitment after logging of dipterocarp forests in Sabah, Malaysia. Biotropica 1996; 28(1): 2-12.

[33] Ewel JJ, Chai P, Lim MT. Biomass and floristics of three young second-growth forests in Sarawak. Malay Forest 1983; 46(3): 34764.

[34] Lim MT, Hamzah MB. Biomass accumulation in a naturally regenerating lowland secondary forest and an Acacia mangium stand in Sarawak. Pertanika 1985; 8(2): 237-42.

[35] MacKinnon K, Sumardja E. Forests for the future: conservation in Kalimantan. In: Padoch C, Peluso NL, Eds. Borneo in Tansition: people, forests, conservation and development, Oxford: Oxford University Press 1996; pp. 59-75.

[36] Sarawak State Government. Sarawak Government Almanac. Kuching: Percetakan Nasional Malaysia Berhad 1999

[37] Google Earth 2009. Available from: http://earth.google.com/ [cited $30^{\text {th }}$ May 2009].

[38] Hashim NR. Anthropogenic tropical forests in the 21st century: the creation, characteristics and uses of secondary forests in Negeri Sembilan, Peninsular Malaysia. PhD [Thesis in Geography]. University of Cambridge, England 2006.

[39] Koh LP, Levang P, Ghazoul J. Designer landscape for sustainable biofuels. Trends Ecol Evol 2009; 24(8); 431-38.

[40] Department of Statistics Malaysia. Annual Bulletin of Sarawak 1960-2000. Kuching: Sarawak Branch 2001.

[41] Appanah S, Weinland G. Planting timber trees in peninsular Malaysia: a review. Kuala Lumpur: forest research institute Malaysia 1993.

[42] Hatch T. Shifting cultivation in Sarawak: a review. Kuching: soil research unit, Sarawak Forest Department 1982.

[43] Lanly JP. Assessment of the forest resources of the tropics. Forest Abstr 1983; 44(6): 287-318.

[44] Padoch, C, Peluso, NL. Changing resource rights in managed forests of West Kalimantan. In: Padoch C, Peluso NL, Eds. Borneo in Tansition: people, forests, conservation and development, Oxford: Oxford University Press 1996; pp. 1-9.

(C) Nor Rasidah Hashim; Licensee Bentham Open.

This is an open access article licensed under the terms of the Creative Commons Attribution Non-Commercial License (http://creativecommons.org/licenses/by$\mathrm{nc} / 3.0 /$ ) which permits unrestricted, non-commercial use, distribution and reproduction in any medium, provided the work is properly cited. 